\title{
An Application of Integrability and Duality Theory to the Classical Transfer Problem in International Trade
}

\author{
John S. ChIPMAN* \\ University of Minnesota
}

\section{Introduction and Background}

A classic problem in the theory of international trade, going back to John Stuart Mill (1844, pp. 41-3), is that of showing that if one country makes a unilateral transfer of funds to another, not only will it lose by the amount of the transfer, but it will also suffer a "secondary burden" of worsened terms of trade, i.e., lower prices of its exports relative to its imports. This is known as the "classical transfer problem." Mill's thesis was disputed by Ohlin (1928, $1929)$ but defended by Keynes $(1929,1930)$ in their debate on the effects of the German reparations payments to the Allied Powers after the First World War.

In Samuelson's $(1952,1954)$ classic treatment the idealization was used (as a way of taking account of transport costs) that commodities deteriorated en route from one country to another. In Chipman (1974) I replaced this by the idealization introduced by Taussig (1927) of nontraded goods, assuming traded goods to be tradable with zero transport costs. In Chipman (1989) I took up the particular case of constant costs in production (the basic assumption made by Mill), in a model in which each of the two countries produces an export good and a nontradable good with a single factor of production (say labor), but relies on imports for the remaining good. I used the concept of a "tradeutility function" developed in Chipman $(1979,1981)$, in which country $k$ 's trade utility is defined as a function, $\hat{U}^{k}\left(z_{1}^{k}, z_{2}^{k}\right)$, of its "trades" (import quantity if positive, export quantity if negative), and the concept of country $k$ 's tradedemand function $z^{k}=\hat{h}^{k}\left(p_{1}, p_{2}, D^{k}\right)$, expressed as a function of the the prices of the two tradables and of the deficit in its balance of payments on current account (this function being generated by maximization of the trade-utility

\footnotetext{
*I wish to thank the referees for their detailed and helpful comments.
} 
function subject to the balance-of-payments constraint $\left.p_{1} z_{1}^{k}+p_{2} z_{2}^{2} \leqq D^{k}\right)$. Assuming that country 1 makes a transfer of $T=-D^{1}=D^{2}$ (expressed in a common currency unit) to country 2 , the condition for the transfer to worsen the paying country's terms of trade $p_{1} / p_{2}$ is the following generalization of Samuelson's $(1952,1954)$ well-known condition: ${ }^{1}$

$$
\frac{\partial \hat{h}_{2}^{2}}{\partial D^{2}}>\frac{\partial \hat{h}_{2}^{1}}{\partial D^{1}}
$$

The hypothesis of constant costs implies that the prices of goods produced in country $k$ satisfy $p_{k} / p_{3}^{k}=b_{k}^{k} / b_{3}^{k}$, where $b_{k}^{k}$ is the amount of labor required per unit of output of country $k$ 's export good and $b_{3}^{k}$ the amount of labor per unit of output of its nontradable good, and $p_{3}^{k}$ is the price of country $k$ 's nontradable good. Assuming the resource-allocation condition $b_{k}^{k} y_{k}^{k}+b_{3}^{k} y_{3}^{k}=l^{k}$ to be satisfied (where $y_{j}^{k}$ is the output of commodity $j$ in country $k$ and $l^{k}$ is country $k$ 's endowment of labor), the trade-demand functions for country $k$ were shown in Chipman (1989) (see also Chipman, 1981) to have the form

$$
\begin{aligned}
& z_{j}^{k}=\hat{h}_{j}^{k}\left(p_{1}, p_{2}, D^{k}\right) \equiv h_{j}^{k}\left(p_{1}, p_{2}, p_{k} \frac{b_{3}^{k}}{b_{k}^{k}}, p_{k} \frac{l^{k}}{b_{k}^{k}}+D^{k}\right) \quad(j \neq k), \text { and } \\
& z_{k}^{k}=\hat{h}_{k}^{k}\left(p_{1}, p_{2}, D^{k}\right) \equiv h_{k}^{k}\left(p_{1}, p_{2}, p_{k} \frac{b_{3}^{k}}{b_{k}^{k}}, p_{k} \frac{l^{k}}{b_{k}^{k}}+D^{k}\right) \\
&-\frac{l^{k}}{b_{k}^{k}}+\frac{b_{3}^{k}}{b_{k}^{k}} h_{3}^{k}\left(p_{1}, p_{2}, p_{k} \frac{b_{3}^{k}}{b_{k}^{k}}, p_{k} \frac{l^{k}}{b_{k}^{k}}+D^{k}\right),
\end{aligned}
$$

where $h_{j}^{k}\left(p_{1}, p_{2}, p_{3}^{k}, Y^{k}\right)$ is country $k$ 's ordinary (Marshallian) demand function for commodity $j$, and $Y^{k}$ is country $k$ 's national income. Accordingly, the partial derivatives in (1.1) evaluate to

$$
\frac{\partial \hat{h}_{j}^{k}}{\partial D^{k}}=\frac{\partial h_{j}^{k}}{\partial Y^{k}}(j \neq k) \quad \text { and } \quad \frac{\partial \hat{h}_{k}^{k}}{\partial D^{k}}=\frac{\partial h_{k}^{k}}{\partial Y^{k}}+\frac{b_{3}^{k}}{b_{k}^{k}} \frac{\partial h_{3}^{k}}{\partial Y^{k}} \quad(k=1,2) .
$$

Thus, the inequality (1.1) becomes

$$
\frac{\partial h_{2}^{2}}{\partial Y^{2}}+\frac{b_{3}^{2}}{b_{2}^{2}} \frac{\partial h_{3}^{2}}{\partial Y^{2}}>\frac{\partial h_{2}^{1}}{\partial Y^{1}} .
$$

\footnotetext{
${ }^{1}$ Samuelson's formula (see also Mundell, 1960) is
}

$$
\frac{\partial h_{2}^{2}}{\partial Y^{2}}>\frac{\partial h_{2}^{1}}{\partial Y^{1}}
$$

where $Y^{k}$ is country $k$ 's national income and $h_{j}^{k}\left(p_{1}, p_{2}, Y^{k}\right)$ is its Marshallian demand function for commodity $j$. Samuelson gave it the interpretation that each country has a preference for its own export good. If there are no nontradable goods, formula (1.1) of the text reduces to Samuelson's formula. 
Our object is to characterize the consumer preferences that satisfy (1.4), independently of $b_{3}^{2} / b_{2}^{2}$.

It is clear that a sufficient condition for (1.4) to hold is that

$$
\frac{\partial h_{2}^{2}}{\partial Y^{2}}=\frac{\partial h_{2}^{1}}{\partial Y^{1}} \quad \text { and } \quad \frac{\partial h_{3}^{2}}{\partial Y^{2}}>0 .
$$

As long as the second condition of (1.5) holds, a necessary condition for (1.4) to hold for all $b_{3}^{2} / b_{2}^{2}$ is that $\partial h_{2}^{2} / \partial Y^{2} \geqq \partial h_{2}^{1} / \partial Y^{1}$, which is the weak counterpart of Samuelson's condition. It is clearly of greater interest, however, to characterize countries' indirect and direct utility functions which generate demand functions that satisfy (1.5). The equality in (1.5) corresponds - as far as commodity 2 is concerned-to Keynes's dictum (1929, p. 2): "If £1 is taken from you and given to me and I choose to increase my consumption of precisely the same goods as those of which you are compelled to diminish yours, there is no Transfer Problem." In this spirit we may apply the same reasoning to the other tradable commodity.

To this end let us first note that (1.4) is equivalent to the inequality

$$
\frac{\partial h_{1}^{1}}{\partial Y^{1}}+\frac{b_{3}^{1}}{b_{1}^{1}} \frac{\partial h_{3}^{1}}{\partial Y^{1}}>\frac{\partial h_{1}^{2}}{\partial Y^{2}} .
$$

This follows from differentiation of the budget identities $p_{1} \hat{h}_{1}^{k}+p_{2} \hat{h}_{2}^{k}=D^{k}$ with respect to $D^{k}$ for $k=1,2$, yielding

$$
p_{1}\left(\frac{\partial \hat{h}_{1}^{1}}{\partial D^{1}}-\frac{\partial \hat{h}_{1}^{2}}{\partial D^{2}}\right)=p_{2}\left(\frac{\partial \hat{h}_{2}^{2}}{\partial D^{2}}-\frac{\partial \hat{h}_{2}^{1}}{\partial D^{1}}\right)
$$

whence (1.6) follows from (1.1) and (1.3). From the same reasoning as above we may adopt the stronger sufficient conditions

$$
\frac{\partial h_{1}^{1}}{\partial Y^{1}}=\frac{\partial h_{1}^{2}}{\partial Y^{2}} \quad \text { and } \quad \frac{\partial h_{3}^{1}}{\partial Y^{1}}>0 .
$$

We shall therefore explore the consequences of adopting the assumptions

$$
\begin{aligned}
\frac{\partial h_{i}^{1}\left(p_{1}, p_{2}, p_{3}^{1}, Y^{1}\right)}{\partial Y^{1}} & =\frac{\partial h_{i}^{2}\left(p_{1}, p_{2}, p_{3}^{2}, Y^{2}\right)}{\partial Y^{2}} & & (i=1,2) \text { and } \\
\frac{\partial h_{3}^{k}}{\partial Y^{k}} & >0 & & (k=1,2) .
\end{aligned}
$$

This is the object of the present paper.

The analysis relies heavily on the treatment of the integrability problem given in Chipman and Moore (1990), which in turn relies on the basic results of Samuelson (1950), McKenzie (1957), and Hurwicz and Uzawa (1971). It will be assumed throughout that countries' preferences are aggregable and locally insatiable and that demand and utility functions are continuously differentiable. 


\section{Characterization of Indirect Utility Func- tions Representing the Countries' Preferences}

Theorem 1. Conditions (1.8) imply that the indirect utility function of the consumers in each country $k$ has the form

$$
V^{k}\left(p^{k}, Y^{k}\right)=A^{k}\left(p^{k}\right)+B\left(p^{k}\right) Y^{k},
$$

where $p^{k}=\left(p_{1}, p_{2}, p_{3}^{k}\right)$ and where $A^{k}$ is convex and positively homogeneous of degree 0 , and $B$ is convex and positively homogeneous of degree 1 , and has the form

$$
B\left(p_{1}, p_{2}, p_{3}^{k}\right)=\frac{1}{a C_{0}\left(p_{1}, p_{2}\right)^{\theta_{0}}\left(p_{3}^{k}\right)^{\theta_{3}}},
$$

where $a>0, C_{0}$ is concave and positively homogeneous of degree 1 , and $\theta_{0}>0$, $\theta_{3}>0$, and $\theta_{0}+\theta_{3}=1$.

PROOF: Since (1.8) must hold for all values of the arguments $\left(p_{1}, p_{2}, p_{3}^{1}, Y^{1}\right)$ and $\left(p_{1}, p_{2}, p_{3}^{2}, Y^{2}\right)$ of the respective functions $\partial h_{i}^{1} / \partial Y^{1}$ and $\partial h_{i}^{2} / \partial Y^{2}$, and these arguments have only $p_{1}$ and $p_{2}$ in common, it follows that $\partial h_{i}^{k} / \partial Y^{k}$ must be independent of $p_{3}^{k}$ and $Y^{k}$ for $i, k=1,2$, and identical with one another as functions of $p_{1}$ and $p_{2}$. Thus, there exist functions $\psi_{i}\left(p_{1}, p_{2}\right)(i=1,2)$ such that

$$
\frac{\partial h_{i}^{k}}{\partial Y^{k}}=\psi_{i}\left(p_{1}, p_{2}\right) \quad(i, k=1,2) .
$$

Integrating these equations we obtain for some functions $\varphi_{i}^{k}$

$$
h_{i}^{k}\left(p_{1}, p_{2}, p_{3}^{k}, Y^{k}\right)=\varphi_{i}^{k}\left(p_{1}, p_{2}, p_{3}^{k}\right)+\psi_{i}\left(p_{1}, p_{2}\right) Y^{k} \quad \text { for } i, k=1,2 .
$$

From the budget equation $\sum_{i=1}^{3} p_{i}^{k} h_{i}^{k}\left(p^{k}, Y^{k}\right)=Y^{k}$ it follows that

$$
h_{3}^{k}\left(p_{1}, p_{2}, p_{3}^{k}, Y^{k}\right)=\varphi_{3}^{k}\left(p_{1}, p_{2}, p_{3}^{k}\right)+\psi_{3}\left(p_{1}, p_{2}, p_{3}^{k}\right) Y^{k}
$$

where

$$
\begin{aligned}
\varphi_{3}^{k}\left(p_{1}, p_{2}, p_{3}^{k}\right) & =-\frac{\sum_{i=1}^{2} \varphi_{i}^{k}\left(p_{1}, p_{2}, p_{3}^{k}\right)}{p_{3}^{k}} \text { and } \\
\psi_{3}\left(p_{1}, p_{2}, p_{3}^{k}\right) & =\frac{1-\sum_{i=1}^{2} \psi_{i}\left(p_{1}, p_{2}\right)}{p_{3}^{k}}
\end{aligned}
$$

From the positive homogeneity of degree 0 of each $h_{i}^{k}\left(p_{1}, p_{2}, p_{3}^{k}, Y^{k}\right)$ it follows that $\varphi_{i}^{k}\left(p_{1}, p_{2}, p_{3}^{k}\right)$ and $\psi_{i}\left(p_{1}, p_{2}, p_{3}^{k}\right)$ are positively homogeneous of degree 0 and -1 respectively, for $i=1,2,3$. 
We denote the Slutsky terms by

$$
s_{i j}^{k}=\frac{\partial h_{i}^{k}}{\partial p_{j}^{k}}+\frac{\partial h_{i}^{k}}{\partial Y^{k}} h_{j}^{k} .
$$

From (2.2) and (2.3) we obtain

$$
s_{i j}^{k}=\frac{\partial \varphi_{i}^{k}}{\partial p_{j}}+\psi_{i} \varphi_{i}^{k}+\left[\frac{\partial \psi_{i}}{\partial p_{j}}+\psi_{i} \psi_{j}\right] Y^{k} .
$$

Setting $s_{i j}^{k}=s_{j i}^{k}$ this leads to

$$
\frac{\partial \varphi_{i}^{k}}{\partial p_{j}}-\varphi_{i}^{k} \psi_{j}=\frac{\partial \varphi_{j}^{k}}{\partial p_{i}}-\varphi_{j}^{k} \psi_{i} \quad \text { and } \quad \frac{\partial \psi_{i}}{\partial p_{j}}=\frac{\partial \psi_{j}}{\partial p_{i}} \quad \text { for } \quad i, j=1,2,3
$$

In particular, since from $(2.2)$ we have $\partial \psi_{i} / \partial p_{3}^{k}=0$ for $i=1,2$, it follows from (2.7) that $\partial \psi_{3} / \partial p_{i}=0$ for $i=1,2$, hence $\psi_{3}^{k}$, and therefore $p_{3}^{k} \psi_{3}^{k}\left(p_{1}, p_{2}, p_{3}^{k}\right)$, is independent of $p_{1}$ and $p_{2} ;^{2}$ thus we have

$p_{3}^{k} \psi_{3}^{k}\left(p_{3}^{k}\right)=1-\sum_{i=1}^{2} \psi_{i}\left(p_{1}, p_{2}\right)=$ constant $\equiv 1-\theta_{0}=\theta_{3} \quad$ (independently of $k$ )

where $0<\theta_{3}<1$ since, as we have assumed, the nontradable is a normal good in both countries. Thus we have

$$
\psi_{3}\left(p_{3}^{k}\right)=\theta_{3} / p_{3}^{k}
$$

Having obtained the above properties of the demand functions, let us now integrate them to obtain the corresponding indirect utility functions for $k=1,2$ (cf. Chipman \& Moore 1990, pp. 105-9). First, in view of the second equation of (2.7), there exists a twice-differentiable function $\Psi\left(p_{1}, p_{2}, p_{3}^{k}\right)$ satisfying the differential equation

$$
\frac{\partial \Psi\left(p^{k}\right)}{\partial p_{i}^{k}}=\psi_{i}\left(p^{k}\right)
$$

Defining

$$
B\left(p^{k}\right)=\exp \left[-\Psi\left(p^{k}\right)\right]
$$

\footnotetext{
${ }^{2}$ While, to be sure, the dependency relation $p_{3}^{k}=b_{3}^{k} p_{k} / b_{k}^{k}$ holds in this model, we are here limiting ourselves to examining the properties of demand functions satisfying (1.8) where the independent variables are free to vary independently subject to those assumptions, hence in this sense $p_{3}^{k}$ is independent of $\left(p_{1}, p_{2}\right)$.
} 
we verify that

$$
-\frac{1}{B\left(p^{k}\right)} \frac{\partial B\left(p^{k}\right)}{\partial p_{i}^{k}}=\psi_{i}\left(p^{k}\right) .
$$

Now consider the system of partial differential equations

$$
\frac{\partial A^{k}\left(p^{k}\right)}{\partial p_{i}^{k}}=-B\left(p^{k}\right) \varphi_{i}^{k}\left(p^{k}\right)
$$

We verify from (2.10) and the first equation of (2.7) that

$$
\frac{\partial^{2} A^{k}\left(p^{k}\right)}{\partial p_{i}^{k} \partial p_{j}^{k}}=\frac{\partial^{2} A^{k}\left(p^{k}\right)}{\partial p_{j}^{k} \partial p_{i}^{k}}
$$

(cf. Chipman \& Moore 1990, pp. 106-7). Thus the system (2.12) has a solution. Finally, let us define the function (2.1), where $p^{k}=\left(p_{1}, p_{2}, p_{3}^{k}\right) .{ }^{3}$ We verify from (2.12) and (2.11) that

$$
\frac{\partial V^{k}}{\partial p_{i}^{k}}=\frac{\partial A^{k}\left(p^{k}\right)}{\partial p_{i}^{k}}+\frac{\partial B\left(p^{k}\right)}{\partial p_{i}^{k}} Y^{k}=-B\left(p^{k}\right)\left[\varphi_{i}^{k}\left(p^{k}\right)+\psi_{i}\left(p^{k}\right)\right] Y^{k}
$$

and

$$
\frac{\partial V^{k}}{\partial Y^{k}}=B\left(p^{k}\right)
$$

hence by Antonelli's partial differential equation (1886, p. 17; 1971, p. 349, equation $(24))^{4}$

$$
-\frac{\partial V^{k}\left(p^{k}, Y^{k}\right) / \partial p_{i}^{k}}{\partial V^{k}\left(p^{k}, Y^{k}\right) / \partial Y^{k}}=\varphi_{i}^{k}\left(p^{k}\right)+\psi_{i}\left(p^{k}\right) Y^{k} \equiv h_{i}^{k}\left(p^{k}, Y^{k}\right) .
$$

Therefore $V^{k}$ is an indirect utility function representing country $k$ 's preferences.

Being an indirect utility function, $V^{k}$ must be convex in $p^{k}$ and positively homogeneous of degree 0 in $\left(p^{k}, Y^{k}\right)$. Consequently, $A^{k}\left(p^{k}\right)$ must be convex and positively homogeneous of degree 0 and $B\left(p^{k}\right)$ must be convex and positively homogeneous of degree -1 . Now from (2.9) and (2.7) we have

$$
\frac{\partial^{2} \Psi\left(p^{k}\right)}{\partial p_{i} \partial p_{3}^{k}}=0 \quad \text { for } \quad i=1,2,
$$

\footnotetext{
${ }^{3}$ This form is due to Gorman (1961) and is known as the "Gorman polar form" (Blackorby, Boyce, \& Russell 1978). The form (2.2) is due to Gorman (1953) and Nataf (1953), and in fact goes back to Antonelli (1886; 1971, pp. 344-5).

${ }^{4}$ See also Allen (1933, p. 190) and Roy (1942, p. 21).
} 
From (2.9) and (2.8) we have

$$
\frac{\partial \Psi\left(p_{1}, p_{2}, p_{3}^{k}\right)}{\partial p_{3}^{k}}=\frac{\theta_{3}}{p_{3}^{k}} .
$$

Integrating (2.14) and taking account of (2.13) and the condition $\partial \Psi / \partial p_{i}=\psi_{i}$ for $i=1,2$ from (2.9), we obtain

$$
\Psi\left(p_{1}, p_{2}, p_{3}^{k}\right)=\alpha+\Phi\left(p_{1}, p_{2}\right)+\theta_{3} \log p_{3}^{k} .
$$

Defining the "cost-of-living function"

$$
C\left(p_{1}, p_{2}, p_{3}^{k}\right)=\frac{1}{B\left(p_{1}, p_{2}, p_{3}^{k}\right)}=\exp \left\{\Psi\left(p_{1}^{k}, p_{2}^{k}, p_{3}^{k}\right)\right\}
$$

it follows from (2.15) that

$$
C\left(p_{1}, p_{2}, p_{3}^{k}\right)=a F\left(p_{1}, p_{2}\right)\left(p_{3}^{k}\right)^{\theta_{3}}
$$

where

$$
a=\exp \{\alpha\} \quad \text { and } \quad F\left(p_{1}, p_{2}\right)=\exp \left\{\Phi\left(p_{1}, p_{2}\right)\right\}
$$

Since $C$ must be concave and positively homogeneous of degree 1 it follows that $F$ must be positively homogeneous of degree $\theta_{0}=1-\theta_{3}<1$. Defining the function

$$
C_{0}\left(p_{1}, p_{2}\right)=F\left(p_{1}, p_{2}\right)^{1 / \theta_{0}}
$$

it follows from (2.16) that $C_{0}$ is positively homogeneous of degree 1 . Thus, (2.17) may be written as

$$
C\left(p_{1}, p_{2}, p_{3}^{k}\right)=a C_{0}\left(p_{1}, p_{2}\right)^{\theta_{0}}\left(p_{3}^{k}\right)^{\theta_{3}} \quad \text { where } \theta_{0}+\theta_{3}=1
$$

\section{Characterization of Direct Utility Function Representing a Country' Homothetic Pref- erences}

Since in this section I shall build on the result of the previous section, in order to economize on notation I shall deal with a single country and dispense with the $k$ superscripts.

When an indirect utility function $V(p, Y)$ has the Antonelli-Nataf-Gorman form (2.1), it is in general not possible to express its dual direct utility function $U(x)$ in an explicit closed form. This is, however, possible in the special case in 
which preferences are homothetic, hence $\varphi_{i}\left(p_{1}, p_{2}, p_{3}\right)=0$ and thus $A(p)=0$, so that (2.1) becomes

$$
V(p, Y)=\frac{Y}{C(p)}=\frac{Y}{a C_{0}\left(p_{1}, p_{2}\right)^{\theta_{0}}\left(p_{3}\right)^{\theta_{3}}} .
$$

The reason for this is that when preferences are homothetic and represented by a homogeneous-of-degree-1 utility function, this utility function and the above-defined cost-of-living function are dual to one another, just as the homogeneous-of-degree- 1 production function and minimum-unit-cost function are dual to one another. Let us explore this duality relationship.

Let the vector-valued demand function $h(p, Y)$ (where $p$ is the price vector and $Y$ is income) be generated by maximizing a homogeneous-of-degree-1 utility function $U(x)$ subject to $p \cdot x \leqq Y$. Then $h(p, Y)$ is homogeneous of degree 1 in $Y$ so $h(p, Y)=Y h(p, 1)$. By definition of an indirect utility function,

$$
V(p, Y)=U[h(p, Y)]=U[Y h(p, 1)]=Y U[h(p, 1)]=\frac{Y}{C(p)},
$$

which defines the cost-of-living function

$$
C(p)=U[h(p, 1)]^{-1} .
$$

The marginal utility of income is then

$$
\frac{\partial V}{\partial Y}=U[h(p, 1)]=\frac{1}{C(p)} .
$$

Now if expenditure $p \cdot x$ is minimized subject to $U(x) \geqq u$, a necessary condition (for an interior solution) is that

$$
\frac{\partial U}{\partial x_{i}}=\frac{p_{i}}{c}
$$

where $c=C(p)$. This is analogous to the condition that the marginal physical productivity of factor $i$ in a particular industry be equal to the ratio of the $i$ th factor rental to the price of the industry's product. In production duality, the analogous condition on the minimum-unit-cost function states that the $i$ th partial derivative of the cost function is equal to the ratio of the $i$ th input to the output. The counterpart of this relation is the condition

$$
\frac{\partial C}{\partial p_{i}}=\frac{x_{i}}{u}
$$

This follows from Antonelli's partial differential equation according to which

$$
h_{i}(p, 1)=-\frac{\partial V(p, 1) / \partial p_{i}}{\partial V(p, 1) / \partial Y}=\frac{\partial C(p) / \partial p_{i}}{C(p)}
$$


(where $\partial V(p, 1) / \partial Y$ means $\partial V(p, Y) / \partial Y$ evaluated at $Y=1$ ) hence

$$
\frac{\partial C(p)}{\partial p_{i}}=h_{i}(p, 1) C(p)=\frac{x_{i}}{U[h(p, 1)]}=\frac{x_{i}}{u} .
$$

First, the following general lemma on homogeneous-of-degree-1 utility functions will be established.

LEMMA. Let $U(x)=U\left(x_{1}, x_{2}, \ldots, x_{n}\right)$ be a concave utility function which is positively homogeneous of degree 1 ; let $x=h(p, Y)$ be the demand function which maximizes $U(x)$ subject to the budget constraint $p \cdot x \leqq Y$, and let $V(p, Y)=U[h(p, Y)]$ be the corresponding indirect utility function; and let $C(p)=1 / V(p, 1)$ be the "cost-of-living function." Then for any $x, p$ maximizes $C(p)$ subject to the same budget constraint. Further,

$$
U(x)=\min _{p}\{x \cdot p \mid C(p) \geqq 1\} \quad \text { and } \quad C(p)=\min _{x}\{p \cdot x \mid U(x) \geqq 1\},
$$

and given any concave and positively homogeneous-of-degree-1 function $C(p)$, letting $p=q(x, Y)$ be the function that maximizes $C(p)$ subject to the above budget constraint, and letting $Q(x, Y)=C[q(x, Y)]$ denote the indirect costof-living function, then $U(x)=1 / Q(x, 1)$.

PROOF: The idea of the proof is indicated in the following chart:

$$
\begin{array}{ll}
\text { Maximize } U(x) \text { s.t. } p \cdot x \leqq Y & \text { Maximize } C(p) \text { s.t. } x \cdot p \leqq Y \\
\mathbb{1} & \\
\text { Minimize } p \cdot x \text { s.t. } U(x) \geqq u & \Longleftrightarrow \text { Minimize } x \cdot p \text { s.t. } C(p) \geqq c
\end{array}
$$

On the left we have the well-known duality between utility maximization subject to a budget constraint and expenditure-minimization subject to a standard-of-living constraint (cf. Debreu 1959, pp. 68-71). On the right we have the same duality with $C(p)$ taking the place of $U(x)$. On the bottom we have the duality theorem of Shephard $(1953,1970)$ and Uzawa (1964) (see also Fuss \& McFadden 1978) - specialized to the case of homogeneous functionswhere $U(x)$ corresponds to the production function and $C(p)$ to the minimumunit-cost function of production theory. (For this specialization see Chipman 1987, p. 924, Theorem 3, showing that $U(x)=\min _{p}\{x \cdot p \mid C(p) \geqq 1\}$ and $C(p)=\min _{x}\{p \cdot x \mid U(x) \geqq 1\}$.) From these three dualities we obtain the duality (equivalence) between the top two problems shown in the chart.

The cost-of-living function $C(p)$ coincides with the usual expenditure function $E(p, u)=\min _{x}\{p \cdot x \mid U(x) \geqq u\}$ evaluated at $u=1$, as well as with the reciprocal of the marginal utility of income $\mu(p, Y)=\partial V(p, Y) / \partial Y$ evaluated at $Y=1$.

The maximization of the cost of living in the statement of the above lemma should not of course be interpreted as a maximization on the part of consumers, but rather as a maximization on the part of Nature with respect to the prices, 
with the quantities taken as fixed..$^{5}$ Alternatively, we may simply refrain from giving this problem an economic interpretation and consider it purely as a mathematical problem.

THEOREM 2. If preferences in both countries are homothetic, (1.8) implies that the countries' utility functions have the form

$$
U\left(x_{1}, x_{2}, x_{3}\right)=U_{0}\left(x_{1}, x_{2}\right)^{\theta_{0}} x_{3}^{\theta_{3}} \quad\left(\theta_{0}>0, \theta_{3}>0, \theta_{0}+\theta_{3}=1\right),
$$

where $U_{0}$ is concave and positively homogeneous of degree 1 . Thus, they are additively separable as between the tradable commodities and the nontradable commodity.

Proof: We shall start by maximizing the given utility function (3.3) with respect to the quantities subject to the budget constraint (with fixed prices) and derive the cost-of-living function, then reverse the steps and maximize the cost-of-living function with respect to the prices subject to the budget constraint (with fixed quantities) and recover the utility function. Maximizing (3.3) subject to the budget constraint $\sum_{i=1}^{3} p_{i} x_{i} \leqq Y$, we obtain the necessary conditions

$$
p_{i}=\frac{\theta_{0}}{\theta_{3}} p_{3} x_{3} \frac{\partial U_{0}\left(x_{1}, x_{2}\right) / \partial x_{i}}{U_{0}\left(x_{1}, x_{2}\right)} \quad \text { for } i=1,2
$$

from which it follows that

$$
Y=\sum_{i=1}^{3} p_{i} x_{i}=\frac{p_{3} x_{3}}{\theta_{3}}
$$

hence

$$
x_{3}=\frac{\theta_{3} Y}{p_{3}} \equiv \tilde{h}_{3}\left(p_{3}, \theta_{3} Y\right) \quad \text { and } \quad Y-p_{3} x_{3}=\theta_{0} Y,
$$

thus obtaining a "sub-demand function" for commodity 3. Since from (3.4) we have

$$
p_{1} x_{1}+p_{2} x_{2}=\theta_{0} Y,
$$

if we maximize $U_{0}\left(x_{1}, x_{2}\right)$ subject to (3.5) we then obtain sub-demand functions for commodities 1 and 2 which we denote

$$
x_{i}=\tilde{h}_{i}\left(p_{1}, p_{2}, \theta_{0} Y\right) \quad(i=1,2) .
$$

\footnotetext{
${ }^{5}$ I owe to Norman Schofield the observation that this analogy of the economic problem to a game between the Consumer and Nature was pointed out by von Neumann $(1938 ; 1945$, p. 5); see also Arrow \& Debreu (1954, p. 285).
} 
The cost-of-living function therefore becomes, from (3.2),

$$
\begin{aligned}
C\left(p_{1}, p_{2}, p_{3}\right) & =\left[U\left(\tilde{h}_{1}\left(p_{1}, p_{2}, \theta_{0}\right), \tilde{h}_{2}\left(p_{1}, p_{2}, \theta_{0}\right), \theta_{3} / p_{3}\right)\right]^{-1} \\
& =\left[U_{0}\left(\tilde{h}_{1}\left(p_{1}, p_{2}, \theta_{0}\right), \tilde{h}_{2}\left(p_{1}, p_{2}, \theta_{0}\right)\right)^{\theta_{0}} \theta_{3}^{\theta_{3}} / p_{3}^{\theta_{3}}\right]^{-1} \\
& =U_{0}\left(\tilde{h}_{1}\left(p_{1}, p_{2}, \theta_{0}\right), \tilde{h}_{2}\left(p_{1}, p_{2}, \theta_{0}\right)\right)^{-\theta_{0}} \theta_{3}^{-\theta_{3}} p_{3}^{\theta_{3}} \\
& =a C_{0}\left(p_{1}, p_{2}\right)^{\theta_{0}} p_{3}^{\theta_{3}}
\end{aligned}
$$

where $^{6}$

$$
a=\theta_{3}^{-\theta_{3}} \quad \text { and } \quad C_{0}\left(p_{1}, p_{2}\right)=\left[U_{0}\left(\tilde{h}_{1}\left(p_{1}, p_{2}, \theta_{0}\right), \tilde{h}_{2}\left(p_{1}, p_{2}, \theta_{0}\right)\right)\right]^{-1} .
$$

Let us now reverse the previous steps and start with a cost-of-living function

$$
C\left(p_{1}, p_{2}, p_{3}\right)=a C_{0}\left(p_{1}, p_{2}\right)^{\theta_{0}}\left(p_{3}\right)^{\theta_{3}} \quad\left(\theta_{0}>0, \theta_{3}>0, \theta_{0}+\theta_{3}=1\right),
$$

where $C_{0}\left(p_{1}, p_{2}\right)$ is concave and positively homogeneous of degree 1 , and maximize (3.7) subject to the constraint $\sum_{i=1}^{3} x_{i} p_{i} \leqq Y$. The steps go through precisely as before. We arrive at the functions

$$
p_{i}=\tilde{q}_{i}\left(x_{1}, x_{2}, \theta_{0} Y\right) \quad(i=1,2), \quad p_{3}=\tilde{q}_{3}\left(p_{3}, \theta_{3} Y\right)=\theta_{3} Y / x_{3},
$$

the first two of which are obtained by maximizing $C_{0}\left(p_{1}, p_{2}\right)$ subject to $x_{1} p_{1}+$ $x_{2} p_{2} \leqq \theta_{0} Y$. In accordance with the Lemma we define $U(x)=C[q(x, 1)]^{-1}$, or

$$
\begin{aligned}
U\left(x_{1}, x_{2}, x_{3}\right) & =\left[C\left(\tilde{q}_{1}\left(x_{1}, x_{2}, \theta_{0}\right), \tilde{q}_{2}\left(x_{1}, x_{2}, \theta_{0}\right), \theta_{3} / x_{3}\right)\right]^{-1} \\
& =\left[a C_{0}\left(\tilde{q}_{1}\left(x_{1}, x_{2}, \theta_{0}\right), \tilde{q}_{2}\left(x_{1}, x_{2}, \theta_{0}\right)\right)^{\theta_{0}} \theta_{3}^{\theta_{3}} / x_{3}^{\theta_{3}}\right]^{-1} \\
& =a^{-1} C_{0}\left(\tilde{q}_{1}\left(x_{1}, x_{2}, \theta_{0}\right), \tilde{q}_{2}\left(x_{1}, x_{2}, \theta_{0}\right)\right)^{-\theta_{0}} \theta_{3}^{-\theta_{3}} x_{3}^{\theta_{3}} \\
& =U_{0}\left(x_{1}, x_{2}\right)^{\theta_{0}} x_{3}^{\theta_{3}}
\end{aligned}
$$

\footnotetext{
${ }^{6} \mathrm{As}$ an example, let $U_{0}\left(x_{1}, x_{2}\right)=x_{1}^{\theta_{1} / \theta_{0}} x_{2}^{\theta_{2} / \theta_{0}}$. Then

$$
\tilde{h}_{i}\left(p_{1}, p_{2}, \theta_{0} Y\right)=\left(\theta_{i} / \theta_{0}\right) \theta_{0} Y / p_{i}=\theta_{i} Y / p_{i}
$$
}

hence

$$
U_{0}\left(\tilde{h}_{1}\left(p_{1}, p_{2}, \theta_{1}\right), \tilde{h}_{1}\left(p_{1}, p_{2}, \theta_{2}\right)\right)=\theta_{1}^{\theta_{1} / \theta_{0}} \theta_{2}^{\theta_{2} / \theta_{0}} p_{1}^{-\theta_{1} / \theta_{0}} p_{2}^{-\theta_{2} / \theta_{0}}
$$

therefore

$$
C_{0}\left(p_{1}, p_{2}\right)^{\theta_{0}}=U_{0}\left(\tilde{h}_{1}\left(p_{1}, p_{2}, \theta_{1}\right), \tilde{h}_{1}\left(p_{1}, p_{2}, \theta_{2}\right)\right)^{-\theta_{0}}=\theta_{1}^{-\theta_{1}} \theta_{2}^{-\theta_{2}} p_{1}^{\theta_{1}} p_{2}^{\theta_{2}}
$$


where

$$
a=\theta_{3}^{-\theta_{3}} \text { and } \quad U_{0}\left(x_{1}, x_{2}\right)=\left[C_{0}\left(\tilde{q}_{1}\left(x_{1}, x_{2}, \theta_{0}\right), \tilde{q}_{1}\left(x_{1}, x_{2}, \theta_{0}\right)\right)\right]^{-1} .
$$

Thus we have recovered the original utility function.

The assumption that preferences in the two countries are homothetic, and that the effect of a change in income on demand for either tradable good is the same in the two countries (as specified by (1.8)), has led to the conclusion that the two countries have identical preferences of the form (3.3). This may be expressed by saying that the countries' preferences are additively separable as between the tradables and the nontradable, since there exists a monotone increasing transformation of the function $U$ of (3.3) (namely $\log U$ ) which is of the additively separable form:

$$
\log U\left(x_{1}, x_{2}, x_{3}\right)=\theta_{0} \log U_{0}\left(x_{1}, x_{2}\right)+\theta_{3} \log x_{3} .
$$

\section{References}

Allen, R. G. D. "On the Marginal Utility of Money and Its Application," Economica, 13 (May 1933), 186-209.

Antonelli, G. B. Sulla teoria matematica della economia politica. Pisa: Tipografia del Folchetto, 1886. Facsimile reprint in Giornale degli Economisti e Annali di Economia, Nuova Serie, 10 (May-June 1951), 233-263. English translation, "On the Mathematical Theory of Political Economy," in Chipman, Hurwicz, Richter, and Sonnenschein (1971), 332-364.

Arrow, Kenneth J., and Gerard Debreu. "Existence of an Equilibrium for a Competitive Economy," Econometrica, 22 (July 1954), 265-290.

Blackorby, Charles, Richard Boyce, and R. Robert Russell. "Estimation of Demand Systems Generated by the Gorman Polar Form: A Generalization of the S-Branch Utility Tree," Econometrica, 46 (March 1978), $345-363$.

Chipman, John S. "The Transfer Problem Once Again," in George Horwich and Paul A. Samuelson (eds.), Trade, Stability, and Macroeconomics: Essays in Honor of Lloyd A. Metzler (New York: Academic Press, 1974), 19-78.

Chipman, John S. "The Theory and Application of Trade Utility Functions," in Jerry R. Green and José Alexandre Scheinkman (eds.), General Equilibrium, Growth, and Trade: Essays in Honor of Lionel McKenzie (New York: Academic Press, 1979), 277-296. 
Chipman, John S. "A General-Equilibrium Framework for Analyzing the Responses of Imports and Exports to External Price Changes: An Aggregation Theorem," in Günter Bamberg and Otto Opitz (eds.), Methods of Operations Research, Vol. 44: 6th Symposium on Operations Research, Universität Augsburg, September 7-9, 1981, Vol. 2 (Königstein: Verlag Anton Hain, Meisenheim GmbH, 1981), 43-56.

Chipman, John S. "International Trade," in John Eatwell, Murray Milgate, and Peter Newman (eds.), The New Palgrave: A Dictionary of Economics, Vol. 2 (London: The Macmillan Press, and New York: The Stockton Press, 1987), 922-955.

Chipman, John S. "The Classical Transfer Problem and the Theory of Foreign Exchanges," in George R. Feiwel (ed.), Joan Robinson and Modern Economic Theory (Houndmills, Basingstoke, Hampshire and London: The Macmillan Press Ltd., 1989), 739-773.

Chipman, John S., Leonid Hurwicz, Marcel K. Richter, and Hugo F. Sonnenschein (eds.). Preferences, Utility, and Demand. New York: Harcourt Brace Jovanovich Inc., 1971.

Chipman, John S., and James C. Moore. "Acceptible Indicators of Welfare Change, Consumer's Surplus Analysis, and the Gorman Polar Form," in John S. Chipman, Daniel McFadden, and Marcel K. Richter (eds.), Preferences, Uncertainty, and Optimality: Essays in Honor of Leonid Hurwicz (Boulder: Westview Press, 1990), 68-120.

Debreu, Gerard. Theory of Value. New York: John Wiley \& Sons, Inc., 1959.

Fuss, Melvyn, and Daniel McFadden (eds.). Production Economics: A Dual Approach to Theory and Applications, Vol. 1. Amsterdam: North Holland Publishing Company, 1978.

Gorman, W. M. "Community Preference Fields," Econometrica, 21 (January 1953), 63-80.

Gorman, W. M. "On a Class of Preference Fields," Metroeconomica, 13 (August 1961), 53-56.

Hurwicz, Leonid, and Hirofumi Uzawa. "On the Integrability of Demand Functions," in Chipman, Hurwicz, Richter, and Sonnenschein (1971), $114-148$.

Keynes, John Maynard. "The German Transfer Problem." Economic Journal 39, (March 1929), 1-7. "A Rejoinder," 39 (June 1929), 179-182. 
Keynes, John Maynard. A Treatise on Money, 2 vols. London: Macmillan, 1930.

McKenzie, Lionel W. "Demand Theory Without a Utility Index," Review of Economic Studies, 24 (June 1957), 185-189.

Mill, John Stuart. Essays on Some Unsettled Questions of Political Economy. London: John W. Parker, 1844.

Mundell, Robert A. "The Pure Theory of International Trade," American Economic Review, 50 (March 1960), 67-110.

Nataf, André. "Sur des questions d'agrégation en économétrie," Publications de l'Institut de Statistique de l'Université de Paris, 2 (Fasc. 4, 1953), 5-61.

Neumann, John von. "Über ein ökonomisches Gleichungssystem und eine Verallgemeinerung des Brouwerschen Fixpunktsatzes," Ergebnisse eines mathematischen Kolloquiums, 8 (1935-36), 73-83. English translation, "A Model of General Economic Equilibrium," Review of Economic Studies, 8 (No. 1, 1945), 1-9.

Ohlin, Bertil. "The Reparations Problem," Index (Svenska Handelsbanken, Stockholm), No. 28, 1928, 2-33.

Ohlin, Bertil. "Transfer Difficulties, Real and Imagined," Economic Journal, 39 (June 1929), 172-178.

Roy, René. De l'utilité. Contribution à la théorie des choix. Paris: Hermann \& $\mathrm{C}^{\mathrm{ie}}$, Éditeurs, 1942.

Samuelson, Paul A. "The Problem of Integrability in Utility Theory," Economica, N.S., 17 (November 1950), 355-385.

Samuelson, Paul A. "The Transfer Problem and Transport Costs: The Terms of Trade when Impediments are Absent," Economic Journal, 62 (June 1952), 278-304.

Samuelson, Paul A. "The Transfer Problem and Transport Costs, II: Analysis of Effects of Trade Impediments," Economic Journal, 64 (June 1954), 264-289.

Shephard, Ronald W. Cost and Production Functions. Princeton: Princeton University Press, 1953. Second printing, Berlin, Heidelberg, and New York: Springer-Verlag, 1981. 
Shephard, Ronald W. Theory of Cost and Production Functions. Princeton: Princeton University Press, 1970.

Taussig, Frank W. International Trade. New York: The Macmillan Company, 1927.

Uzawa, Hirofumi. "Duality Principles in the Theory of Cost and Production," International Economic Review, 5 (May 1964), 216-220. 